\title{
Das Glück der Banane
}

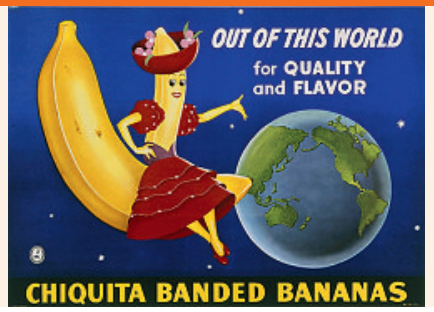

Erhard Taverna

Bananen sind vieles. Sie sind Genuss- und Heilmittel, Kunstobjekt und politische Metapher, Sexsymbol und einfach nur gesund. Sie bieten leichtverdauliche Kohlenhydrate und Vitamine, einen hohen Kaliumgehalt und Neurotransmitter wie Serotonin und Dopamin. Begleitprodukte wie Textilien aus Staudenblättern bereichern Modekreationen, und selbst das Transportmittel, die praktische Bananenschachtel, ist seit Generationen beim Umzug unentbehrlich. Kaum ein Produkt ist mit allen seinen Widersprüchen und Paradoxien geeigneter als Sinnbild dieser globalisierten Welt der Gegenwart.

Die Weltwirtschaftspflanze gedeiht in den Monokulturen des tropischen und subtropischen Klimas, wo jährlich rund 100 Millionen Tonnen geerntet werden. Seit 1904 bringen Kühlschiffe die begehrte Luxusfrucht nach Europa, bis zu 530000 Kartons pro Dampfer. Inzwischen zum Billigangebot unserer Supermärkte gehörend, gelangt sie vom Reifeschlaf der Kühlketten in die Reifereien der Grossverteiler, wo bei aufsteigenden Temperaturen ab 14 bis zu 18 Grad Celsius und Zugabe von Äthylen 20\% der Stärke in Zucker umgewandelt werden. Die Länder der EU sind weltweit die Hauptabnehmer der botanischen Beere, von der es an die tausend Sorten, aber nur wenige Marken gibt. Ein Abstecher in die Botanik illustriert, wie unser Gebrauch dieser Nutzpflanze den zukünftigen Konsum gefährdet. Durch Selektion und Kreuzungen entstand die hybride Form der Dessertbanane «Musa paradisiaca» mit den bekannten Sorten «Gros Michel» und «Cavendish». Wie viele andere triploide Hybride sind auch diese Obstbananen steril, sie vermehren sich vegetativ über Stecklinge, was eine geringe genetische Variabilität zur Folge hat. Der Anbau der wenig resistenten Früchte wird durch Pilzkrankheiten, Viren, Bakterien und Nematoden gefährdet. Eine Kulturpflanze, die zu unserer Gesundheit beiträgt, ist wegen der grossräumigen Monokulturen, trotz Agrochemie, massiv gefährdet. Vielleicht verschwindet sie gar eines Tages von unserem Speiseplan.

Doch vorläufig ist die Banane immer noch ein unverzichtbarer Teil unserer Alltagskultur. Seit 1944, als die United Fruit Company die «Miss Chiquita» erfand, gehört ihre gelb-blaue Bekleidung zum universalen Warenkosmos. Die Banane hat eine knallige Farbe und einen lustigen Namen, sie ist sympathisch und verlockend. Josephine Baker erfreute in den 20er Jahren ihr Publikum, spärlich bekleidet, mit ihrem berühmt-berüchtigten Bananentanz. Sambamusik, Jazz und frivole Bananenröckchen stehen für Exotik und Erotik, unverzichtbar für viele PR-Aktionen, die das Öffnen eines Reissverschlusses mit dem Schälen gleichsetzen. Andy Warhol entdeckte in den 60ern den Kunstwert der Normbanane, die seither in immer neuen Variationen zum Kunstbetrieb gehört. Es gibt unzählige Bananensongs, Musicals und Filmszenen, die in irgendeiner Form von dieser Frucht inspiriert sind. Der Witz vom Ausrutscher auf der Bananenschale ist uralt und bekannt. Er hat seit Buster Keaton seinen festen Platz im Repertoire der Filmbranche. Auch die Politik kann sich der Frucht nicht entziehen. Niemand möchte in einer «Bananenrepublik» wohnen, doch vor dem Fall der Mauer war die Banane ein Symbol der kapitalistischen Überlegenheit über die Mangelwirtschaft des Ostens.

Die Ausstellung «going Bananas» im Vögele Kultur Zentrum in Pfäffikon bietet eine optimale Gelegenheit, die vielfältigen Bezüge dieser krummen Frucht zu Kultur, Kult und Kunst anschaulich aufzuzeigen. Den Kuratorinnen ist es hervorragend gelungen, ethnobotanische Fragestellungen und komplexe Sachverhalte auf einem Rundgang szenografischübersichtlich zu gliedern. Ein verderbliches Alltagsobjekt mit beschränkter Lebensdauer wird auf einzigartige Weise zum Mittelpunkt einer faszinierenden Auseinandersetzung mit unserer Zivilisation. Marktwirtschaft, Gourmetfreuden, Ökologie und Politik werden auf eine lustvolle Art, gegenständlich und audiovisuell transparent gemacht. Die Ausstellung will kulturinteressierte Menschen, Familien und Jugendliche ansprechen. Dafür gibt es auch ein Begleitprogramm mit verschiedenen Veranstaltungen für Erwachsene und Kinder.

Ein heisser Tipp für die beginnenden Sommerausflüge: Alpamare mit Gratisbananen im Kulturzentrum nebenan. Bequem und rasch ab dem Bahnhof mit dem Bus erreichbar.

\section{«going Bananas»}

Die Ausstellung findet statt bis zum 21. August 2011 im Vögele Kultur Zentrum, in Pfäffikon SZ. Das Textheft zur Ausstellung ist im Eintrittspreis inbegriffen. Weitere Informationen finden sich unter www.voegelekultur.ch und im Vögele Kultur Bulletin «going Bananas», Ausgabe 90/2011. 